\title{
Revisão do processo de solicitação de exames laboratoriais nas Unidades Básicas de Saúde administradas pelo HIAE
}

\author{
Hospital Israelita Albert Einstein
}

\section{INTRODUÇÃO}

A busca pela qualidade nas organizações de saúde tem requerido melhorias contínuas e a obtenção de bons resultados. A solicitação apropriada de exames é um componente essencial no processo de tomada de decisão pelo profissional médico. Historicamente, a sua ordenação tem sido realizada de maneira não padronizada e indiscriminada, de forma automática, por hábito, sem a preocupação em limitar o número de exames e sem levar em consideração os seus custos e riscos. Estima-se que $30 \%$ de todos os pedidos de exames laboratoriais são desnecessários e que os outros $30 \%$ são subutilizados. Os dados são resultado de um estudo publicado por pesquisadores da Harvard Medical School a partir da análise de 1,6 milhão de resultados dos 46 testes de laboratórios mais solicitados por médicos e instituições de saúde. Em 13 UBS da região sul, durante o ano de 2016, foram solicitados, em média, 2,47 exames por consulta, gerando um custo médio de R\$11,45 por consulta, o que significa em um total de 330.714 consultas a solicitação de 816.544 exames coletados a um custo de $\mathbf{R} \$ 3.786 .517,89$

\section{OBJETIVO}

Descrever o processo de melhoria implantado para revisar o processo de solicitação de exames laboratoriais nas UBS visando uma redução do número de exames laboratoriais desnecessários e consequentemente, dos respectivos custos.

\section{MÉTODO}

Esse projeto baseia-se no número total de exames laboratoriais solicitados pelos médicos atuantes nas 13 UBS administradas pelo Hospital Israelita Albert Einstein e o custo total relacionado. Os indicadores utilizados foram número total de exames laboratoriais sobre o número total de consultas médicas; custo total relacionado a solicitação de exames laboratoriais sobre o número de consultas médicas; processo de exames laboratoriais revisado, validado e implantado. O projeto exclui os exames laboratoriais solicitados nas unidades AMA, CAPS e UPA administradas pelo parceiro Einstein; exclui as solicitações de exames de sorologia; exclui as solicitações de exames laboratoriais por profissionais não médicos (enfermeiro, dentista, etc). Foi desenvolvido dashboard na plataforma NISI-Online para inserção do banco de dados. Mensalmente as 13 UBS enviam os relatórios de fechamento do serviço de coleta laboratorial para o NISI, onde os dados são consolidados e disponibilizados para consulta. A metodologia foi baseada nos conceitos Lean Six Sigma, através das fases de Definição, Medição, Análise, Melhoria e Controle.

\section{RESULTADO}

A média de exames por consulta na UBS Jd. das Palmas, apresentou uma redução de $37 \%$ e, a redução dos custos por consulta atingiu $44 \%$.

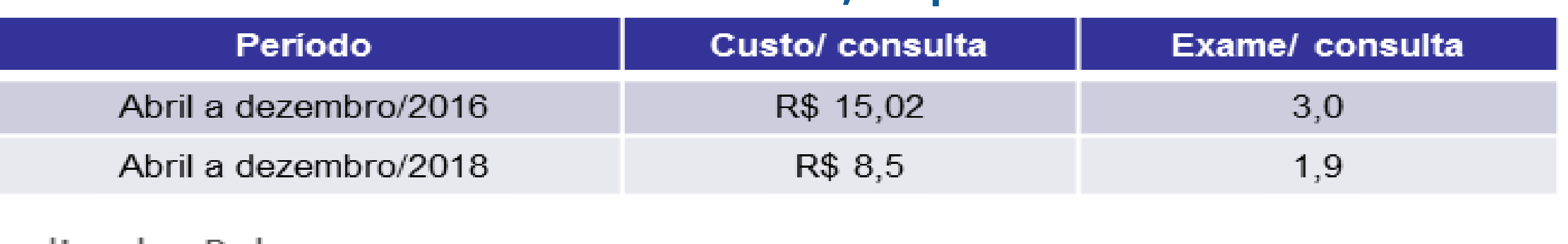

Custo por consulta na UBS Jardim das Palmas

Período: Abril a Dezembro/2016 e Abril a Dezembro/2018

Exames por Consulta na UBS Jardim das Palmas

$$
\text { - } 2016=2018
$$
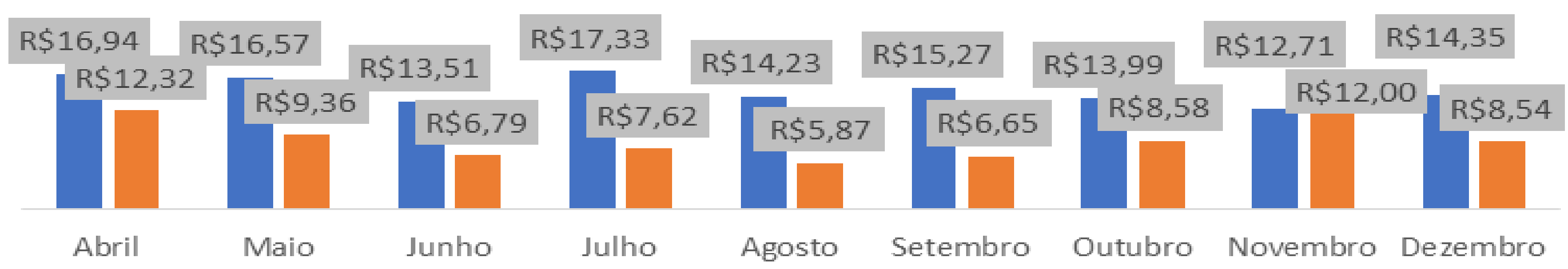

Comparando o período de 8 meses entre 2016 e 2018 foram solicitados 16.504 (44\%) exames a menos, que gerou uma economia de $\mathrm{R} \$ 95.735,20$ (40\%).

\begin{tabular}{|c|c|c|}
\hline \multicolumn{3}{|c|}{ Projeção Anual } \\
\hline Unidade & $\begin{array}{c}\text { Redução do número } \\
\text { de exames (ano) }\end{array}$ & $\begin{array}{c}\text { Redução de custo total } \\
\text { (ano) }\end{array}$ \\
\hline UBS Jd. Das Palmas & 25.825 & $R \$ 150.003$ \\
\hline 13 UBS Einstein"t & 335.935 & $R \$ 1.950 .039$ \\
\hline 453 UBS PMSP*t & 11.698 .725 & $R \$ 67.951 .359$ \\
\hline
\end{tabular}

Custo total na UBS Jardim das Palmas

Período: Abril a Dezembro/2016 e Abril a Dezembro/2018 - $2016=2018$

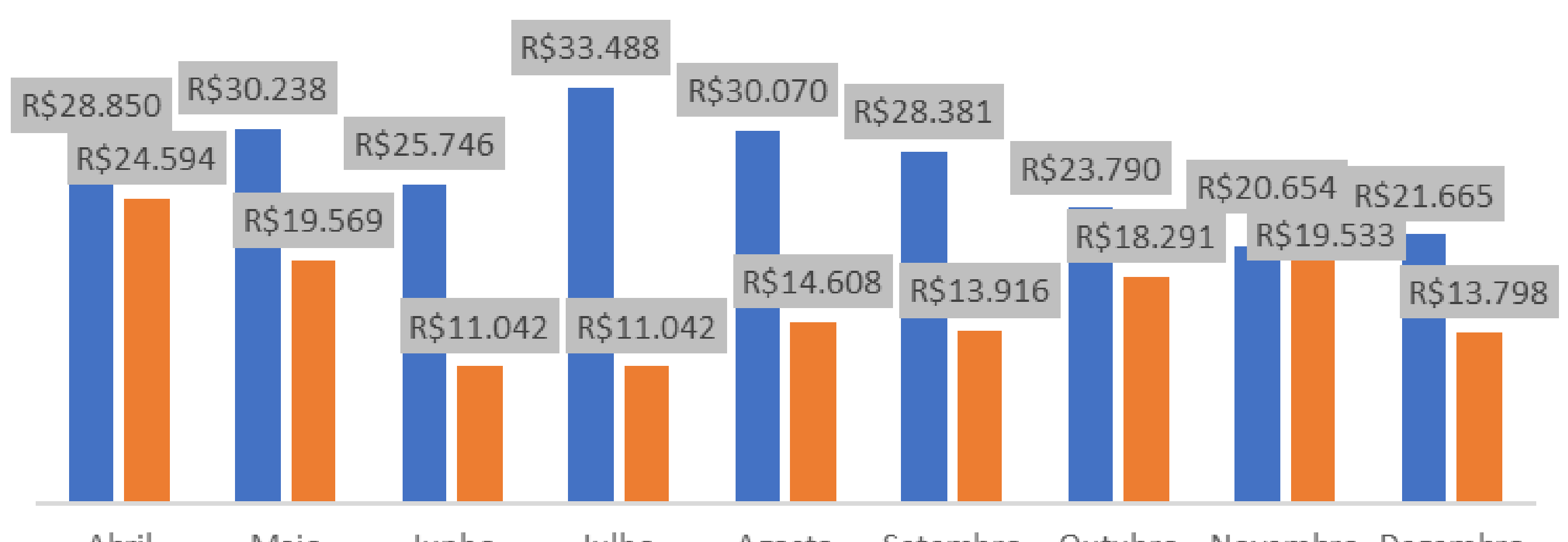

Período: Abril a Dezembro/2016 e Abril a Dezembro/2018 - $2016=2018$

\section{CONSIDERAÇÕES FINAIS}

Com o uso da metodologia Lean Six Sigma, foi possível rever o fluxo de solicitação dos exames laboratoriais pelos médicos da UBS Jd. das Palmas e reduzir o volume de solicitações, bem como o custo gerado para o sistema.

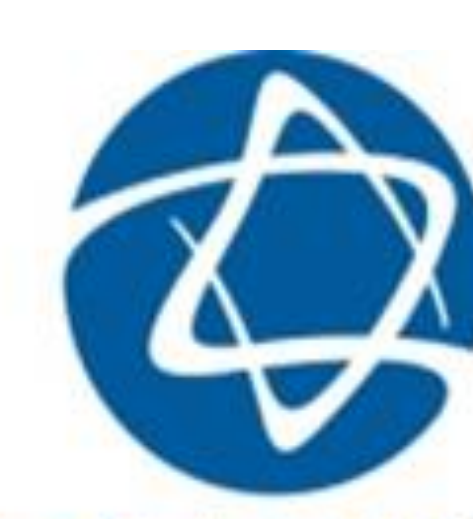

ALBERT EINSTEIN

SOCIEDADE BENEFICENTE ISRAELITA BRASILEIRA HOSPITAL - ENSINO E PESQUISA - RESPONSABILIDADE SOCIAL

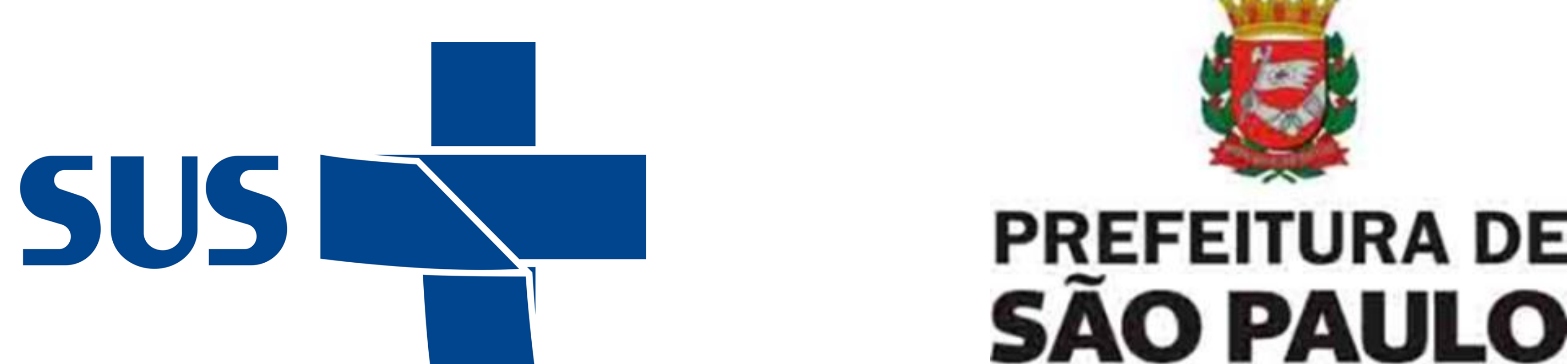

SAÚDE 